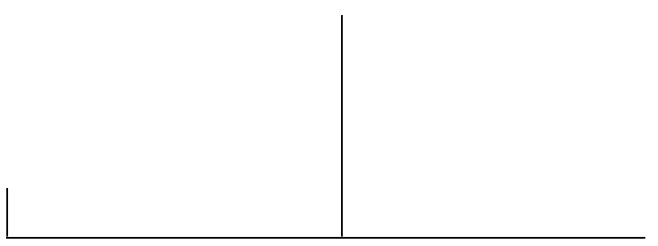

Rev. Latinoam. Psicopat. Fund., São Paulo, v. 13, n.3, p. 522-527, setembro 2010

Maslach, Christina, Schaufeli, Wilmar \& Leiter, Michael Job Burnout

Annual Review of Psychology, n. 52, p. 397-422, 2001

Sartorius, Norman et al. Progress Toward Achieving a Common Language in Psychiatry: results from the field trial of the clinical guidelines Arquives of General Psychiatry, v. 50, n. 2, p. 115-124, February 1993

Silveira, Julliane

Brasileiros estão entre os mais estressados do globo Folha.com (Folha de S. Paulo), 14 de julho de 2010, Equilíbrio e Saúde

Freudenberger, Hernert J.

Staff Burn-Out

Journal of Social Issues, v. 30, n. 1, p. 159-165, 1974

\title{
Como nascem as classificações
}

Guilherme Gutman

Sempre nos pareceu acertada a frase de Norman Sartorius - então diretor da Divisão de Saúde Mental da OMS - na introdução ao capítulo referente aos transtornos mentais e de comportamento da CID-10: "Uma classificação é um modo de ver o mundo de um ponto no tempo". Todavia, a frase de Sartorius parece sutilmente contradita pelo próprio espírito da classificação que o seu texto se propôs a introduzir.

É que se a CID-10 corresponde à "aquisição de uma linguagem comum em psiquiatria" (Sartorius et al., 1993), o seu modo de elaboração 
- uma espécie de consenso entre especialistas; ou talvez fosse melhor dizer, uma conversação, em âmbito mundial, muito bem regrada e hierarquizada, na qual, grosso modo, foram estabelecidas as categorias nosológicas que permaneceriam na então nova edição (e, portanto, também a determinação das categorias que "desapareceriam") e seus respectivos critérios diagnósticos - carrega tacitamente a expectativa de que, nessa empreitada "classificante", caminha-se na direção de uma linguagem mais pura, refinada ou precisa. Sob o conceito da confiabilidade que, num certo sentido, de fato implicaria uma, digamos, língua que todos fossem capazes de falar - dos confins da Mongólia à nossa Terra Brasilis - há a presença de outros elementos mais velados: entre estes, sobretudo a ideia de que, se ao classificarmos estamos "olhando para o mundo de um ponto no tempo", nosso olhar classificador, no ritmo de cada nova classificação, deslizaria para $o$ alto e avante! Quer dizer, embora se reconheça que o nosso olhar é sempre condicionado pela nossa época, e que na próxima (e, por razões que deveriam nos interessar, eternamente adiada) décima-primeira edição da CID, já veremos o mundo de outra forma, há todo um júbilo mal contido na perspectiva de que, se olhamos para trás, é para, olhos no futuro, vermos mais além, "sobre os ombros de gigantes" (numa versão mais épica e reverencial aos clássicos) ou por sobre a obtusidade, equívoco ou envelhecimento daquele que poderia ser chamado de "olhar CID-10".

Tal expectativa, que é a de uma linguagem mais precisa, pode certamente ser compreendida como tributária de uma outra e maior expectativa: a de que o "progresso da ciência" - expressão tão gasta quanto, muitíssimas vezes, sedutora e convincente - proporcionará às classificações, novas “descobertas", novos métodos ou exames complementares que, por sua vez, implicarão na obtenção de um efeito de precisão; isto é, a psiquiatria supostamente colocaria um fim, finalmente (ou, ainda como parte do pacote de expectativas, muito perto de um "finalmente"), à sua nostalgia de uma objetividade nosográfica, perdida um dia nos descaminhos de uma psicopatologia mais filosófica que científica.

Este vaivém entre a objetividade e a subjetividade dos conceitos, tão característico e familiar às disciplinas afins à psicopatologia, é notavelmente presente - conforme estamos sugerindo - na elaboração de uma classificação, em especial em todo o itinerário percorrido por um determinado quadro clínico, aspirante ao status de categoria classificatória.

\section{Os nervos cansados}

Seria natural que se pensasse o ponto de origem das classificações - e da nomenclatura empregada em suas categorias - como oriundas de alguma classi- 
ficação arcaica, meio perdida no tempo. A manobra necessária, então, seria quase a de uma escavação arqueológica, da qual, cobertas de pó e terra, surgiriam as classificações elaboradas por um Pinel (1745-1826) ou por um Esquirol (17721840). Mas, obviamente, a respeito do resgate histórico desses pioneiros, foi preciso que se perdesse uma certa ingenuidade epistemológica que gostaria de ver nos mapas nosográficos dos clássicos, capítulos ultrapassados que serviriam, apenas, para contar a história triunfante de uma psiquiatria que caminharia numa trilha retilínea e ascendente. Nesta linha de revisão histórica das classificações, sempre haverá espaço para a menção dos trabalhos de Bercherie (1989), nos quais a dita ingenuidade epistemológica é revertida em favor de uma historiografia psiquiátrica na qual está presente um campo dinâmico, no qual cada época buscou homogeneidade e consistência classificatórias. Diz ele, a respeito da tarefa de releitura dos clássicos:

[Trata-se], antes de mais nada, de evitar um obstáculo que permanece como a cruz de todas as pesquisas históricas em psicologia: a leitura do passado nos termos do presente, que, com a busca dos precursores, parece haver desaparecido dos modernos trabalhos de epistemologia, mas ainda floresce em nossa disciplina. Certamente não é fácil restituir a autores já antigos o sentido real de sua orientação, sem introduzir de imediato o que neles pode ser lido por quem os descortina do alto de todo um tempo histórico; (...) eles observavam (os fatos) e questionavam sob um ângulo específico, impossível de superpor diretamente àquele sob o qual os abordamos agora. É esse ângulo particular de abordagem dos fenômenos que dá sentido ao desenvolvimento histórico, e em cada etapa é preciso tentar redescobrir o que parecia adquirido... (p. 26)

Neste sentido, a CID-9, quando oposta à CID-10, não deveria ser lida como um capítulo obsoleto da história recente das classificações; ao contrário, têm-se mais a ganhar quando se retorna a cada uma das categorias presentes na embolorada CID-9 - especialmente aquelas categorias que se ausentaram da edição seguinte - e se procura entender que novas exigências clínicas (ou de outra espécie) fizeram com que algo da conduta classificatória se modificasse em relação a elas.

Há como possibilidade, na passagem da CID-10 ao mapa diagnóstico que virá em seguida a ela, que uma categoria específica - a neurastenia - desapareça e que uma outra categoria - o burnout - faça uma entrada mais consistente na classificação. No caso da neurastenia, a sugestão de que se trata, possivelmente, de uma categoria em extinção é reforçada pelo fato de que, embora mantida na CID-10, já não se presentifica na DSM-IVtr - classificação esta que, como se sabe, aspira com ainda mais voracidade a uma precisão diagnóstica que suporta mal categorias com critérios vagos, ou mal delimitadas em suas fronteiras definitórias, em favor de entidades nosológicas que pudessem ser fixadas segundo 


\section{RESENHA}

"critérios classificatórios científicos", especialmente aqueles derivados dos métodos e resultados das neurociências.

É exatamente neste ponto que deve incidir uma observação que nos parece relevante: embora, como havíamos reconhecido, os clássicos estejam na origem do vocabulário em que formulamos no presente as nossas hipóteses diagnósticas, as suas categorias classificatórias não são produto de tubos de ensaio dos laboratórios dos velhos alienistas; há uma passagem - cuja negligência implica sempre miopias ou estrabismos na percepção da natureza das classificações - que é a absorção pela linguagem do dia a dia das categorias psicopatológicas e, numa espécie de refluxo, a reabsorção, pelas classificações dessas categorias, agora já deglutidas e digeridas por seu uso corrente; o técnico e o leigo. Há também o extrativismo - por parte dos "classificadores" - de expressões, ou mesmo sugestões de categorias que "nasceram de baixo para cima", ou seja, que surgiram da experiência clínica e cotidiana dos pacientes e seus médicos, formuladas em um vocabulário que mescla a conceitualmente rigorosa terminologia psicopatológica com uma outra psicopatologia - a popular - que tinge com as cores cotidianas do real, a trama da clínica nossa de cada dia. Então, é preciso notar que a presença (ou a extinção) de uma categoria diagnóstica em uma classificação será também o produto desse intercâmbio entre dois extratos em que elas terão circulado: o extrato da linguagem ordinária e o extrato do vocabulário científico.

Vale, nessa direção, a lembrança de uma pesquisa realizada na década de 1980, no Brasil, ${ }^{1}$ na qual se interrogava o dito caráter essencial da doença e se propunha, como perspectiva alternativa, que os transtornos também pudessem ser compreendidos como ficções tecidas em linguagem e tornadas reais exatamente por sua apropriação técnica e leiga. ${ }^{2}$

Este intercâmbio entre os dois extratos acima mencionados, remetem também às questões filológicas concernentes ao trânsito entre a dita língua erudita - aquelas que aprendemos nas gramáticas - e a língua popular, com seus "erros"

1. Alguns resultados dessa pesquisa estão em Costa (1989).

2. A respeito da experiência que foi a matriz clínica e institucional da pesquisa, escreve o autor: "Boa parte da clientela que afluía aos ambulatórios psiquiátricos (do então chamado, Centro Psiquiátrico Pedro II, no Engenho de Dentro - bairro da Zona Norte do Rio de Janeiro) queixava-se de um mal-estar cuja sintomatologia clínica driblava a nosografia tradicional: a doença dos nervos. O fato não era novo. Há muito os profissionais dos serviços públicos conheciam o quadro. Mas limitavam-se a prescrever psicotrópicos ou a constatar a incapacidade dos clientes de se submeterem à psicoterapia. (...) A crença no valor universal da classificação nosográfica e de uma certa representação do aparelho psíquico segundo a psicanálise avalizam, por assim dizer, outras opiniões preconceituosas" (Costa, 1989, p. 17-18). 




e invenções, incorporadas a cada nova edição dos grandes dicionários contemporâneos da língua portuguesa, como o Aurélio ou o Houaiss.

\section{Burning out}

Pelo livro de Ballet (1906), que ocupa um lugar intermediário entre os clássicos e as atuais classificações, ficamos sabendo que a neurastenia - esse cansaço dos nervos - teve o seu ponto de origem num precursor chamado Beard (1839-1883), que lançou as bases para a composição desse quadro clínico: "uma doença moderna criada pela sobrecarga intelectual e moral inerente à civilização e à vida social de nossa época" (Beard, 1906, p. 7). A ideia de que as exigências excessivas da modernidade podem ser causadoras de uma espécie de exaustão algo que na linguagem comum poderia ser chamada de "estafa" - aflora como categoria nosográfica nos escritos oitocentistas de Beard e, desafiando as épocas, atravessa classificações e faz-se notar, com alguma frequência, em jornais e revistas dirigidas ao grande público. Nesses veículos, matérias como "Brasileiros estão entre os mais estressados do globo" (Silveira, 2010) podem ser lidas exatamente como registros do entrelaçamento da terminologia médica e da linguagem jornalística - esta mais próxima do vocabulário comum - na formulação dos quadros clínicos. Mais do que isso, uma matéria como essa da Folha.com, pode ser entendida, não como uma notícia "atrasada" de algo que "a ciência já sabia", mas como algo que pode eventualmente preceder a fixação de uma determinada entidade diagnóstica. No seguinte trecho, a jornalista escreve:

Os brasileiros lidam pior com o estresse do que outros povos. Por aqui, as taxas daquilo que é definido como estresse extremo são mais altas que na maioria do países.

Esse último nível de estresse, ou burn out, caracteriza-se por um esgotamento mental intenso, geralmente associado ao trabalho. (grifos nossos)

O burnout surge acima como uma categoria informal e híbrida; surge no texto quase como uma expressão colhida nas ruas, utilizada para a designação da nocividade potencialmente associada à sobrecarga - em especial aos excessos vinculados às exigências do trabalho. Não é, portanto, tão surpreendente quando, ao lermos o texto inaugural de Freudenberger (1974) sobre o burnout, descobrimos que esta é uma dessas síndromes que surgem "de baixo para cima":

Há poucos anos, alguns de nós que vínhamos trabalhando intensamente (...) começamos a falar de um conceito que chamamos de "burn-out". Tendo eu mesmo experimentado este estado de burn out, comecei a me colocar um certo número de questões.

Rev. Latinoam. Psicopat. Fund., São Paulo, v. 13, n. 3, p. 522-527, setembro 2010 
O dicionário define o verbo "burn-out" como "falhar (...) ou tornar-se exausto por ter feito demandas excessivas de energia, força ou recursos". E isso é exatamente o que acontece quando o membro de uma equipe (de trabalho) burns out por qualquer razão que seja tornando-se inoperante..." (Freudenberger, 1974, p. 159-160)

Maslach - também em um artigo pioneiro e autorreferido sobre a síndrome - muitos anos depois, procura dar a essa expressão, que era usada correntemente na década de 1970 por trabalhadores estafados, estatuto de transtorno específico: "Burnout é uma resposta prolongada a estressores interpessoais e emocionais crônicos no trabalho, definida pelas três dimensões: exaustão, cinismo e ineficácia" (Maslach, Schaufeli \& Leiter, 2001, p. 397).

Pode ser que estejamos sendo testemunha do nascimento de mais uma categoria nosográfica.

Até a próxima edição!

\section{Outras Referências}

Ballet, G. Hygiene du Neurasthenique. Paris: Masson, 1906.

BERCHERIE, P. Os fundamentos da clínica: história e estrutura do saber psiquiátrico. Rio de Janeiro: Zahar, 1989.

Costa, J.F. Psicanálise e contexto cultural: imaginário psicanalítico, grupos e psicoterapias. Rio de Janeiro: Campus, 1989.

OMS. Classificação de Transtornos Mentais e de Comportamento da CID-10. Porto Alegre: Artes Médicas, 1993.

\section{GUILHERME GutMan}

Psiquiatra e psicanalista; doutor em saúde coletiva pelo Instituto de Medicina Social da Universidade do Estado do Rio de Janeiro - UERJ (Rio de Janeiro, RJ, Brasil); professor adjunto do Departamento de Psicologia da Pontifícia Universidade Católica do Rio de Janeiro - PUCRio (Rio de Janeiro, RJ, Brasil).

Rua Visconde de Pirajá, 595/905 - Ipanema.

22410-003 Rio de Janeiro, RJ, Brasil

Fone: (21) 9106-7009

e-mail: guilhermegutman@gmail.com 